Original Article

\title{
Analysis of Adulterated Pangasius Hypopthalmus Oil by ATR-FTIR Spectroscopy and Chemometric
}

\author{
Lisa Andina ${ }^{1 *}$, Revita Saputri ${ }^{1}$, Aristha Novyra Putri ${ }^{1}$, Endang Lukitaningsih ${ }^{2}$, Abdul Rohman ${ }^{2}$ \\ 1Department of Pharmacy, Sekolah Tinggi Ilmu Kesehatan Borneo Lestari, Banjarbaru, 70714 Indonesia \\ ${ }^{2}$ Faculty of Pharmacy, Gadjah Mada University, Yogyakarta, 55281 Indonesia \\ *Corresponding author: Lisa Andina I Email: $\underline{\text { lisa imeru@yahoo.com }}$
}

Received: 1 November 2019; Revised: 19 November 2019; Accepted: 27 November 2019; Published: 6 December 2019

\begin{abstract}
In this recent study, ATR-FTIR spectroscopy and chemometrics have been successfully used for the classification and quantitative analysis of adulterated Pangasius Hypopthalmus (P. hypopthalmus) oil. The aim of this research was to evaluate the ability of ATR-FTIR spectroscopy and chemometric to perform the classification and quantitative analysis of adulterated P. hypopthalmus oil in a binary mixture with palm oil (PO) and coconut oil (CO). In the development of FTIR spectroscopy combined with chemometrics for the classification and quantitative analysis of P. hypopthalmus oil, P. hypopthalmus oil (MP and LFP) mixed with other oils such as coconut oil (CO) and palm oil (PO) at concentrations of 1-99\% v/v. Classification of P. hypopthalmus oil, PO and $\mathrm{CO}$ were performed by the principal component analysis (PCA) and the quantification analysis was carried out by partial least square (PLS). Based on the optimization process, the best classification results were obtained using the first derivative spectra at wave numbers of $1400-1100 \mathrm{~cm}^{-1}$. The prediction of percentage adulterated oil by PLS method also showed very good values of $\mathrm{R}^{2}$ greater than 0.9999 and low standard error values in the range of $0.0176-0.703$. The prediction was also perform at $1400-1100 \mathrm{~cm}^{-1}$ wavenumbers using the first derivative spectra.
\end{abstract}

Keywords: Pangasius hypopthalmus oil, ATR-FTIR spectroscopy, chemometric

\section{INTRODUCTION}

Pangasius hypopthalmus (P. hypopthalmus) oil contains polyunsaturated fatty acids (PUFA) which can be beneficial to human health [1,2]. The high production of catfish in Indonesia provides a great opportunity for the production of $P$. hypopthalmus oil [3]. In edible oil trade, oil adulteration has become a global issue. Oil adulteration may cause a decline in terms of oil quality [4-6]. To overcome this issue, the fast and accurate analysis technique is needed to detect the oil adulteration.

Fourier transform infrared (FTIR) spectroscopy is one of the fingerprinting techniques that can be useful in the authentication oil. FTIR spectroscopy measures the vibration of functional groups because of the interaction between electromagnetic radiation and the sample, thus producing spectra with a typical fingerprint area for each sample. Changes occur in components of a sample will be related to changes in the band and the intensity of the FTIR spectrum. However, FTIR spectroscopy has a complex spectrum pattern. Thus, direct and visual interpretation is not easy. Therefore, multivariate analysis using chemometrics was combined with FTIR to make it easier for analysis purpose [7-10]. 
Many studies that combine FTIR fingerprint spectra and chemometrics for the purpose of authentication. Principal component analysis (PCA) as one of the methods in chemometric classifies different samples into groups by factor scores. PCA enables extraction of information that correlates to sample's chemical components and the determination of mixture composition using a few uncorrelated variables (principal components, PC). PCA produces clear information by reducing the dimensionality, this extraction is useful to simplify the complexity of the problem (e.g similar sample composition). PCs represent the highest possible variance under the orthogonality constraint to the preceding components that are linear combinations of the original spectral data. PCA applied to the FTIR spectral data can be used for classification of different sample mixtures [6, 11-15].

Partial least square (PLS) has been widely used for quantitative analysis for the complex mixtures of sample. PLS provides a statistical approach to use the full spectral regions rather than using a specific region. PLS model can be considered as an extension of PCA to multivariate calibration. PLS have 2 different data matrices namely $\mathrm{x}$ and $\mathrm{y}$. The matrix $\mathrm{x}$ normally contains data generated from the actual data, while the matrix y contains data that can inform about the experimental process and is usually referred to as the response matrix. The main goal of PLS is to find the maximum correlation between the $\mathrm{x}$ and $\mathrm{y}$ matrices to make $\mathrm{y}$ predictions in the $\mathrm{x}$ function. PLS applied to the FTIR spectral data can be used for quantitative analysis of adulterated samples [16-20].

This study was conducted to develop a method for rapid qualitative and quantitative analysis of P. hypopthalmus oil adulteration in coconut oil (CO) and palm oil (PO) using ATR-FTIR spectroscopy and chemometrics.

\section{MATERIALS AND METHODS}

\subsection{Sample preparation}

P. hypopthalmus oil divided into two parts based on its source, (1) MP derived from dry rendering of P. hypopthalmus's meat and (2) LFP derived from dry rendering of P. hypopthalmus's liver and fat. Coconut oil (CO) and palm oil (PO) were purchased in Banjarbaru, Indonesia. Each of $\mathrm{MP}$ and LFP were mixed with CO and PO at concentration of $1-99 \% \mathrm{v} / \mathrm{v}$.

\subsection{FTIR spectra measurement}

All samples were measured by FTIR spectrophotometer Nicolet 6700 using Deuterated triglycine sulphate (DTGS) as detector linked with OMNIC software (version 7.0 thermo Nicolet). Sample collection by the attenuated total reflectance (ATR) crystal technique. The measurements were performed at a controlled temperature $\left(20^{\circ} \mathrm{C}\right)$ with the resolution of $4 \mathrm{~cm}^{-1}$ and 32 scans. All spectra were recorded at wavenumbers of $4000-650 \mathrm{~cm}^{-1}$ using absorbance mode in triplicate measurement.

\subsection{Classification}

Classification of P. hypopthalmus oil (MP and LFP), CO and PO was carried out by multivariate analysis using a Principal Component Analysis (PCA) by The Unscrambler X ver. 10.5 software. All samples were measured by FTIR spectrophotometer according to FTIR measurement. The best model were selected based on the PC score.

\subsection{Quantitative analysis}

Quantitative analysis of P. hypopthalmus oil (MP and LFP) in CO and PO was carried out by multivariate analysis using a partial least square calibration (PLS) model using TQ Analyst ver. 9.0 
software. PLS calibration was done by preparing a number of standard samples containing $P$. hypopthalmus oil in CO and PO in the range of 1-99\% v/v. A number of independent samples are prepared for validation. All samples were measured by FTIR spectrophotometer according to FTIR measurement. The best model were selected based on coefficient of determination $\left(R^{2}\right)$, the root mean square error of calibration (RMSEC), and root mean square error of prediction (RMSEP).

\section{RESULTS AND DISCUSSION}

\subsection{FTIR spectra measurement}

FTIR spectroscopy is an analytical technique that provides information on all chemical properties in samples in the form of spectra. As can be seen in figure 1, the spectra of MP, LFP, CO and $\mathrm{PO}$ have a very similar pattern from one another, but it has a difference in the absorbance value. This shows that the composition of the MP, LFP, CO and PO is almost the same.

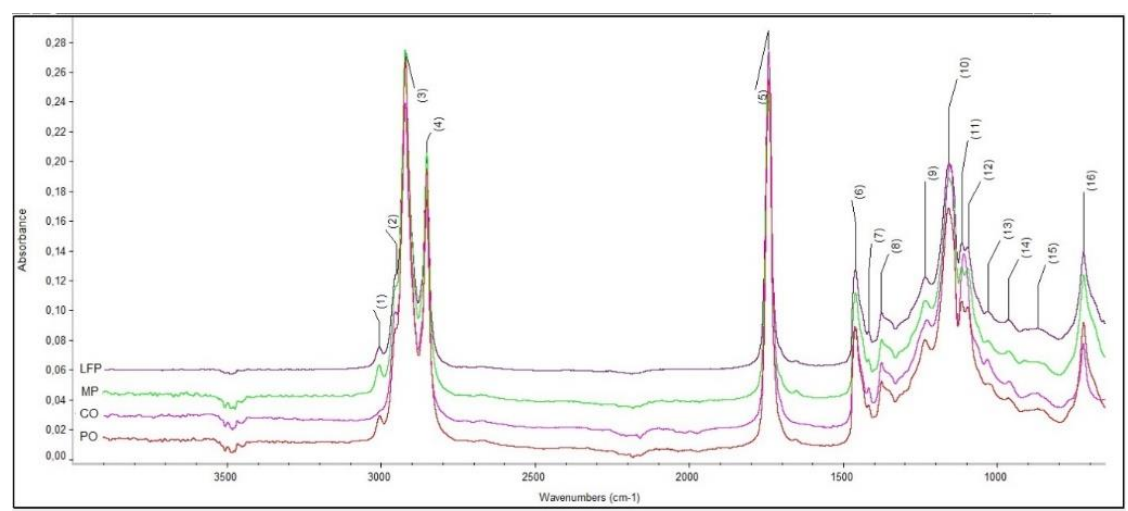

Figure 1. P. hypopthalmus oil (MP and LFP), CO and PO ATR-FTIR spectra

Table 1 shows the typical bands of MP, LFP, CO and PO spectra. The absorptions found in MP, LFP, CO and PO is band at 3005-3006 $\mathrm{cm}^{-1}$ that indicates $\mathrm{C}-\mathrm{H}$ stretching vibration of cisunsaturated bond [3, 21, 22]. Different from MP, LFP and PO spectra, CO spectra do not show this band. Bands (2), (3) and (4) with sharp peaks and adjacent around 2954 and $2852 \mathrm{~cm}^{-1}$ indicate the stretching C-H vibrations of carbon aliphatic group in methyl and methylene [3, 23]. Band (5) at 1742$1744 \mathrm{~cm}^{-1}$ is specifically showed the stretching vibration of $\mathrm{C}=\mathrm{O}[3,22]$. Spectral patterns in fingerprint region at $1400-720 \mathrm{~cm}^{-1}$ are identical, this makes it difficult to distinguish between the four types of oil by only using the FTIR spectrum. Therefore it's necessary to use the chemometrics method where the PCA was applied to the spectroscopic dataset.

Table 1. Bands appear on MP, LFP, CO and PO spectra at certain wavenumber

\begin{tabular}{ccccc}
\hline Band & \multicolumn{4}{c}{ Peak at $\mathbf{~ c m}^{-1}$} \\
\cline { 2 - 5 } & MP & LFP & CO & PO \\
1 & 3006.99 & 3006.67 & - & 3005.35 \\
2 & - & 2954.21 & 2954.84 & - \\
3 & 2922.17 & 2922.11 & 2922.28 & 2922.01 \\
4 & 2852.68 & 2852.95 & 2853.02 & 2852.59 \\
5 & 1743.61 & 1744.33 & 1742.66 & 1743.73 \\
6 & 1461.24 & 1461.87 & 1462.48 & 1461.46 \\
7 & 1418.70 & 1418.70 & 1418.42 & 1416.64 \\
8 & 1376.17 & 1376.60 & 1376.43 & 1376.31 \\
9 & 1234.79 & 1234.23 & 1229.00 & 1235.24 \\
\hline
\end{tabular}




\begin{tabular}{|c|c|c|c|c|}
\hline \multicolumn{5}{|c|}{ Continued Table 1... } \\
\hline 10 & 1158.01 & 1157.48 & 1153.08 & 1159.00 \\
\hline 11 & 1116.18 & 1115.64 & 1109.49 & 1115.94 \\
\hline 12 & 1097.12 & 1098.23 & - & 1097.28 \\
\hline 13 & 1031.47 & 1032.89 & 1033.07 & - \\
\hline 14 & 965.40 & 964.96 & 964.17 & 955.62 \\
\hline 15 & 912.95 & 869.75 & 888.50 & 870.34 \\
\hline 16 & 720.75 & 721.14 & 721.37 & 720.95 \\
\hline
\end{tabular}

\subsection{Classification}

PCA was performed to the normal and first derivative spectral data of the fingerprint region of oils, i.e., 1400-1000 $\mathrm{cm}^{-1}$. Figure 2 shows the full normal spectra of MP, LFP, CO, and PO. Figure 2 also shows normal spectra at $1400-1000 \mathrm{~cm}^{-1}$ and the first derivative spectra at $1400-1000 \mathrm{~cm}^{-1}$ which been selected for optimization process of classification.

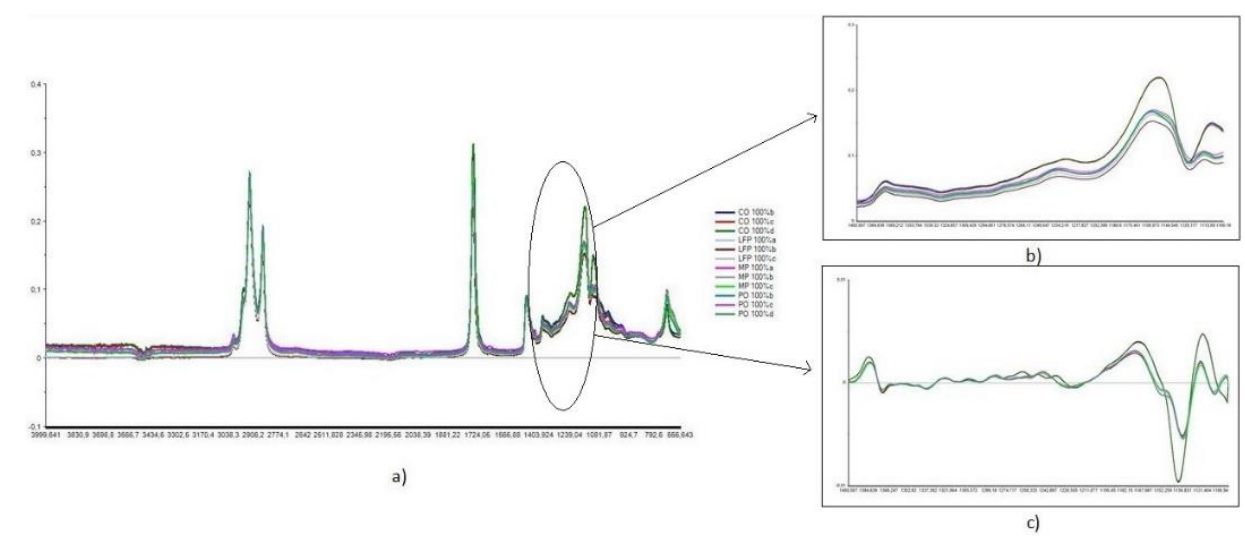

Figure 2. P. Hypopthalmus oil (MP and LFP), CO and PO ATR-FTIR spectra: a) Normal spectra (4000-400 $\left.\left.\mathrm{cm}^{-1}\right) ; b\right)$ Normal spectra $\left(1400-1000 \mathrm{~cm}^{-1}\right) ; \quad$ c) 1st derivative spectra $\left(1400-1000 \mathrm{~cm}^{-1}\right)$

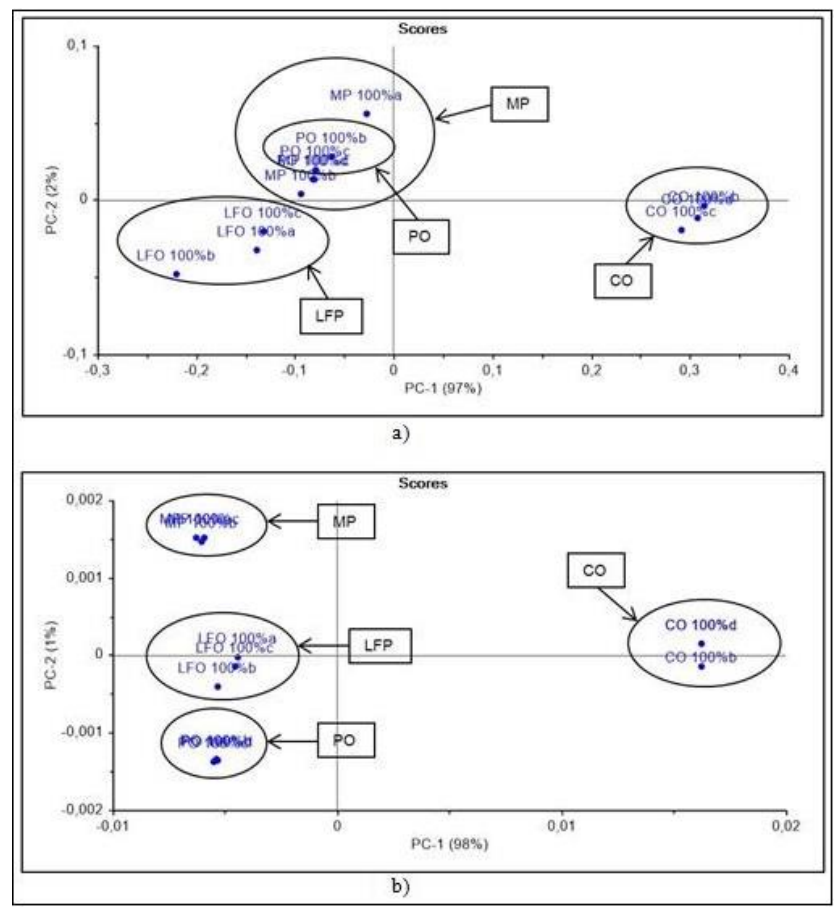

Figure 3. PCA analysis result of $P$. hypopthalmus oil (MP and LFP), CO and PO: a) PCA analysis using normal spectra at $1400-1000 \mathrm{~cm}^{-1}$ : b) PCA analysis using 1st derivative spectra at $1400-1000 \mathrm{~cm}^{-1}$ 
As it can be seen in Figure 3 (a) through the PCA analysis, it was shown that $99 \%$ of data variances were explained (PC-1 $97 \%$ vs PC-2 2\%) by using normal spectra at $1400-1000 \mathrm{~cm}^{-1}$. However, it failed to classified PO and MP into the respective groups. Figure 3 (b) shows the PCA analysis result by using first derivative spectra at the same wavenumber as previous. By using first derivative spectra, it was observed that $99 \%$ of data variances was also explained (PC-1 $98 \%$ vs PC-2 $1 \%$ ) and it successfully have classified LFP, CO, PO and MP as a different groups of oil. PC-1 separate $\mathrm{LFP}, \mathrm{MP}$ and $\mathrm{PO}$, with negative values from $\mathrm{CO}$, in positive values on the score chart. From score chart it also shows that in PC-2 have separate LFP and MP, in positive values from PO in negative values.

\subsection{Quantittative analysis}

Based on the PCA analysis results, furthermore the first derivative spectra at $1400-1000 \mathrm{~cm}^{-1}$ wavenumber also used for the quantification of $\mathrm{CO}$ and PO content in MP and LFP. PLS was used to develop the calibration model. PLS correlates $X$ axis (the actual concentration of adulterant oil (CO and PO) in P. hypopthalmus oil (MP and LFP)) and Y axis (the calculated concentration of adulterant oil (CO and PO) in P. hypopthalmus oil (MP and LFP)). Figure 4 shows the score plot from PLS calibration and the linier equation of calibration models can be seen in table 2. From the optimization process by PLS calibration method, the best $\mathrm{R}^{2}$, RMSEC and RMSEP value were given by using first derivative spectra at $1400-1000 \mathrm{~cm}^{-1}$ wavenumber. The $\mathrm{R}^{2}$ obtained was $0.9999-1.000$, RMSEC in the range of 0.0176-0.7030 and RMSEP in the range of 0.6520-2.4200.

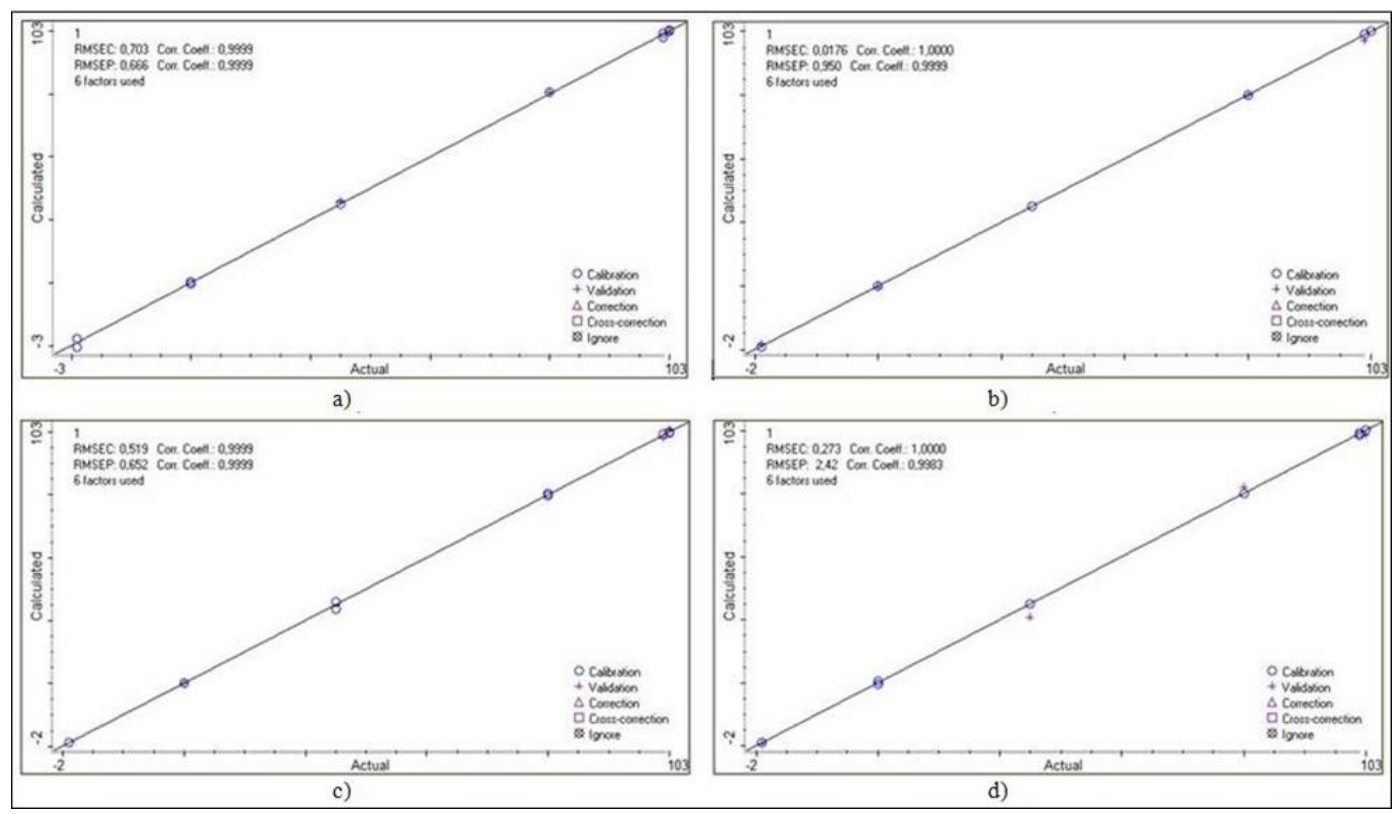

Figure 4. PLS result of first derivative spectra P. hypopthalmus oil in binary mixture at $1400-1000 \mathrm{~cm}^{-1}:$ a) score plot of actual vs calculated levels of added CO in MP; b) score plot of actual vs calculated levels of added PO in MP; c) score plot of actual vs calculated levels of added CO in LFP; d) score plot of actual vs calculated levels of added PO in LFP

Table 2. Linier equation for quantitative analysis of CO and PO in MP and LFP at 1400-1000 cm-1 using PLS calibtration

\begin{tabular}{ccc}
\hline & Linier equation & R2 \\
\hline MP-CO & $\mathrm{y}=0.9991 \mathrm{x}+0.1498$ & 0.9999 \\
MP-PO & $\mathrm{y}=0.9953 \mathrm{x}+0.1629$ & 1.0000 \\
LFP-CO & $\mathrm{y}=0.9991 \mathrm{x}+0.011$ & 0.9999 \\
LFP-PO & $\mathrm{y}=1.0026 \mathrm{x}-0.4495$ & 1.0000 \\
\hline
\end{tabular}


The developed calibration models show satisfying result as can be seen by $\mathrm{R}^{2}$ greater than 0.9999, respectively. This value means that there is a close correlation between the actual concentration value and the calculated concentration value [24]. RMSEC and RMSEP show a low value, this values means that the developed calibration models have a low error rate. This findings indicates that the developed calibration model using ATR-FTIR spectroscopy and PLS chemometric is a valid calibration model and can be used as alternative in the quantification of CO and PO in $P$. hypopthalmus oil. Besides, this method was fast, accurate, relative low cost and does not require a lot of time and energy.

\section{CONCLUSION}

This study indicates that application of PCA the first derivative ATR-FTIR spectra at 1400$1000 \mathrm{~cm}^{-1}$ have been succesfully classified MP, LFP, CO and PO into groups. PLS was showed good performance on the prediction of CO and PO content in MP and LFP at 1400-1000 $\mathrm{cm}^{-1}$ of first derivative spectra. The calibration results $\mathrm{R}^{2}$ greater than 0.9999 and low standard error values in the range of $0.0176-0.7030$.

Funding: This research was funded by Ministry of Research, Technology and Higher Education of Indonesia, Competitive Grants DIPA-042.06.1.401516/2018.

Acknowledgments: The authors thanks to Ministry of Research, Technology and Higher Education of Indonesia, STIKES Borneo Lestari and Gadjah Mada University.

Conflicts of interest: The authors declare no conflict of interest.

\section{Reference}

1. Hastarini, E.; Fardiaz, D.; Irianto, H.E.; Budijanto, S. Characteristics of Fish Oil Produced from Fillet Processing Waste of Siam (Pangasius hypopthalmus) and Jambal (Pangasius djambal) Catfish. Agritech 2012, 32, 403-410.

2. Panagan, A.T.; Yohandini, H.; Gultom, J.U. Analisis Kualitatif dan Kuantitatif Asam Lemak Tak Jenuh Omega-3 dari Minyak Ikan Patin (Pangasius pangasius) dengan metode Kromatografi Gas. Jurnal Universitas Sriwijaya Sumatera Selatan 2011, 14, 38-42.

3. Andina, L.; Saputri, R.; Putri, A.R.; Rohman, A. Infrared Spectroscopy and multivariate calibration for the rapid quantification of free fatty acid content in Pangasius Hypopthalmus oil. Int J App Pharm 2018, 10(6), 199203.

4. Rohman, A.; Che Man, Y.B.; Ismail, A.; Hashim, P. Application of FTIR Spectroscopy for the determination of Virgin Coconut Oil in Binary Mixtures with Olive oil an Palm Oil. J Am Oil Chem Soc 2010, 87(6), 601-606.

5. Rohman, A.; Che Man, Y.B. Application of Fourier Trasform infrared (FT-IR) spectroscopy combined with chemometrics for authentication of cod-liver oil. Vib Spectrosc 2011, 55(2), 141-145.

6. Rohman, A.; Windarsih, A.; Sudjadi, Riyanto, S.; Ahmad, S.A.S.; Rosman, A.S.; Yusoff, F.M. Fourier Transform Infrared Spectroscopy Combined with Multivariate Calibration for the Authentication of Avocado Oil. Int J Food Prop 2016, 19(3), 680-687.

7. Karoui, R.; Downey, G.; Blecker, C. Mid-Infared Spectroscopy Coupled With Chemometrics: A Tool For The Analysis Of Intact Food Systems and The Exploration For Their Molecular Structure-Quality Relationship- A Review. Chemical Review 2010, 110, 6144-6168.

8. Sun, S.; Chen, J.; Zhou, Q.; Lu, G.; Chan, K. Application of mid-infrared spectroscopy in the quality control of traditional chinese medicines. Planta Medica 2010, 76, 1987-1996.

9. Gad, H.A.; El-Hamady, S.H.; Abou-Shoer, M.I.; Al-Azizi, M.M. Application of chemometrics in authentication of herbal medicines: a review. Phytochem Anal 2012, 24, 1-24.

10. Anjos, O.; Campos, M.G.; Ruiz, P.C.; Antunes, P. Application of FTIR-ATR Spectroscopy to The quantification of sugar in honey. Food Chem 2015, 169, 218-223.

11. Nicolaou, N.; Xu, Y.; Goodacre, R. Fourier Transform Iinfrared spectroscopy and multivariate analysis for the detection and quantification of different milk species. J Dairy Sci 2010, 93, 5651-5660. 
12. De Luca, M.; Terouzi, W.; Kzaiber, F.; Ioele, G.; Oussama, A.; Ragno, G. Classification of moroccan olive cultivars by linear discriminant analysis applied to ATR-FTIR spectra of endocarps. Int J Food Sci Technol 2012, 47, 1286-1292.

13. Jovic, O.; Smolic, T.; Jurisic, Z.; Meic, Z.; Hrenar, T. Chemometric Analysis of Croaatian Extra Virgin Olive Oils fromCentral Dalmatia Region. Croat Chem Acta 2013, 86, 335-344.

14. Jaiswal, P.; Jha, S.N.; Borah, A.; Gautam, A.; Grewal, M.K.; Jindal, G. Detection and quantification of soymilk in cow-buffalo milk using Attenuated Total Reflectance-Fourier Transform Infrared spectroscopy ATR-FTIR. Food Chem. 2015, 168, 41-47.

15. Nurrulhidayah, A.F.; Che Man, Y.B.; Rohman, A. Ftir Spectroscopy Combined With Chemometric For Analysis Of Sesame Oil Adulterated With Corn Oil, Food Properties 2014, 17, 1275-1282.

16. Nurrulhidayah, A.F.; Che Man, Y.B.; Al-Kahtani, H.A.; Rohman, A. Application of FTIR spectroscopy coupled with chemometrics for authentication of Nigella sativa seed oil. Spectroscopy, 2011, 25, 243-50.

17. Rohman, A.; Che Man, YB. Application of Fourier Transform Infrared Spectroscopy for Authentication of unctional Food oils. Applied Spectroscopy Review 2012, 47 (1),1-13.

18. Che Man, Y.B.; Rohman, A. Analysis of Canola Oil in Virgin Coconut Oil Using FTIR Spectroscopy and Chemometrics. J Food Pharm Sci, 2013, 1, 5-9.

19. Guntarti A, Martono S, Yuswanto A, Rohman A. FTIR Spectroscopy in Combination with Chemometrics for Analysis of Wild Boar Meat in Meatball Formulation. Asian Journal of Biochem. 2015; 10(4): 165-72.

20. El-Bagary, R.I.; El-Kady, E.; Al-Matari, A. Simultaneous spectrophotometric determination of diclofenac sodium, paracetamol, and chlorzoxazone in ternary mixture using chemometric and artificial neural networks techniques. Asian J Pharm Clin Res 2017, 10(11), 225-230.

21. Guillen, M.D.; Cabo, N. Usefulness of the frequencies of some fourier transform infrared spectroscopic bands for evaluating the composition of edible oil mixtures. Fett Lipid 1999, 101(1), 71-76.

22. Vlachos, N.; Skopelitis, Y.; Psaroudaki, M.; Konstantinidou, V.; Chatzilazarou, A.; Tegou, E. Application of fourier transform-infrared spectroscopy to edible oils. Anal chim acta 2006, 573-574, 459-465.

23. Rohman, A.; Che Man Y.B. FTIR spectroscopy combined with chemometrics for analysis of lard in the mixtures with body fats of lamb, cow and chicken, IFRJ 2010, 17, 519-526.

24. Miller, J.N.; Miller, J.C. Statistics and Chemometrics for Analytical Chemistry, Sixth Edition. Ashford Colour Press Ltd, Gosport, UK, 2010. p. 241-245.

(C) 2019 by the authors. Submitted for possible open access publication under the terms and conditions of the Creative Commons Attribution (CC BY) license (http://creativecommons.org/licenses/by/4.0/). 